\title{
A utilização dos Ambientes Informatizados na rede municipal de Alvorada/RS -
}

\section{Brasil}

\section{The use of Information Environments in the municipal network of Alvorada / RS - Brazil}

\author{
Clayton Moch \\ Prefeitura Municipal de Alvorada/RS - Brasil
}

\begin{abstract}
Resumo
A comunicação oral refere-se a defesa da dissertação de Mestrado que teve como Problema: Como ocorre a utilização dos ambientes informatizados com alunos e professores do ensino fundamental da rede municipal de Alvorada/RS - Brasil? O Objetivo Geral da pesquisa foi: analisar como os professores da rede municipal de ensino de Alvorada utilizam ferramentas pedagógicas de TICs em sala de aula com alunos do $9^{\circ}$ ano do ensino fundamental. Os principais resultados apontam para uma motivação para maior utilização das TIC. Com isso, foi possível destacar aspectos como a necessidade de se rever a formação dos professores com TICs.

Palavras-chave: TIC, processo ensino-aprendizagem, laboratórios de informática, escolas públicas, formação de professores.
\end{abstract}

\begin{abstract}
Oral communication refers to the defense of the Master's dissertation that had as a Problem: How does the use of computerized environments with students and teachers of elementary school of the municipal network of Alvorada / RS - Brazil? The general objective of the research was: to analyze how the teachers of the Alvorada municipal school network use pedagogical tools of ICT in the classroom with students of the 9th year of elementary school. The main results point to a motivation for greater use of ICT. With this, it was possible to highlight aspects such as the need to review the teacher training with ICTs.

Keywords: ICT, teaching-learning process, computer labs, public schools, teacher training.
\end{abstract}

\section{Introdução}

Esta dissertação intitulada A utilização de Ambientes Informatizados (AIs) na rede municipal de Alvorada, visa pesquisar sobre o uso desses recursos presentes nas escolas públicas dos municipais de Alvorada, Rio Grande do Sul, Brasil.

\section{Justificativas}

As justificativas para que fosse pesquisado sobre a utilização dos Ambientes Informatizados na rede municipal de Alvorada deu-se pela vinculação pessoal, científica e sócio-educativa do mestrando com o município.

\section{Pessoal}

Este estudo vem ao encontro de atividades docentes do mestre que sempre estiveram conectadas às Tecnologias da Informação e Comunicação (TICs), pois desde o início da docência, nos anos 2001, o mestre procurou incentivar o uso pelos alunos de novas ferramentas tecnológicas como o computador, celular e câmera digital.

No ano de 2008 o mestrando iniciou uma tutoria EAD no curso de Matemática oferecido pela REGESD, através da UERGS, vinculado até o ano de 2011. Em 2009 começou um curso de especialização EAD em física para a educação básica finalizado no ano de 2011. Neste período conheceu outras ferramentas para serem utilizadas que eram novidades, despertando ainda mais seu interesse nesta área.

No ano de 2013 coordenou o primeiro curso de formação em b-learning para os professores da rede municipal de Alvorada, intitulado: "Práticas Pedagógicas em Ambientes Informatizados", levando toda a experiência e conhecimento nesta área para outros colegas. Este curso veio ao encontro de uma constatação que o mestrando pôde verificar nas escolas: os professores não utilizam os laboratórios de informática como poderiam. Desta forma, acabam sendo subutilizados, sem o aproveitamento de seu verdadeiro potencial como ferramenta pedagógica.

Neste curso foi levado aos colegas tudo que foi aprendido nestes 13 anos de docência, mostrando que a tecnologia é uma aliada importante para o desenvolvimento das aulas, utilizando-a com toda sua qualidade e variedade de instrumentos disponíveis para serem aproveitados.

Com isso podemos despertar um maior interesse por parte dos alunos já que eles estarão utilizando as tecnologias presentes diariamente na vida deles. E também tornando as aulas mais prazerosas, já que os alunos, normalmente, apreciam quando veem uma aula diferente da que estão acostumados, além de se integrarem mais ativamente na utilização das TICs e, consequentemente, no conteúdo desenvolvido na aula. 
Este estudo vem também fortalecer algumas indicações que já apareceram em outros estudos semelhantes, como as relatadas nos parágrafos anteriores, mas principalmente, demonstrar a importância de ser estabelecida uma política de formação continuada relacionada às TICs no município de Alvorada.

\section{Científica}

Os resultados desta pesquisa estarão disponíveis no mundo acadêmico contribuindo para os avanços nos estudos de outros pesquisadores para a utilização dos ambientes informatizados em sala de aula e também para a melhora da qualidade do trabalho docente.

\section{Sócio educacional}

Atualmente, no mundo em que vivemos, a educação básica passa por uma fase de questionamento por parte dos professores, pesquisadores e comunidade escolar, seja por causa dos conteúdos, dos métodos pedagógicos ou pela responsabilidade de cada um na vida do aluno. Com isso, emergem várias indagações sobre estes assuntos, com diversas pesquisas em cada área e com uma busca contínua de respostas para a educação, que no contexto atual encontra na pesquisa um dos caminhos para o entendimento da realidade que se apresenta quanto ao uso dos ambientes informatizados em sala de aula. Neste sentido esta pesquisa contribuirá para a formação dos profissionais que atuam no ensino fundamental utilizando os ambientes informatizados.

\section{Problema}

Como apontam Almeida \& Valente (2011), as mudanças necessárias para promover as TICs ao currículo ainda não aconteceram em nenhum sistema educacional e em Alvorada não poderia ser diferente. Assim, muito embora estejam presentes na vida de cada aluno e professor, seja pelo uso de computador, celular, $\mathrm{TV}$, foto, entre tantos outros aparatos tecnológicos que são utilizados todos os dias, na escola ainda se utiliza muito pouco este tipo de recurso de forma pedagógica.

Nesta dissertação de Mestrado em Educação na área de especialização em Tecnologia Educativa, estudaremos como ocorre a utilização dos ambientes informatizados com alunos e professores do ensino fundamental da rede municipal de Alvorada?

\section{Objetivo geral}

O Objetivo Geral da pesquisa é o seguinte: analisar como os professores da rede municipal de ensino de Alvorada utilizam ferramentas pedagógicas de TICs em sala de aula com alunos do $9^{\circ}$ ano do ensino fundamental.

\section{Objetivos específicos}

E o Objetivo geral desdobra-se nos seguintes objetivos específicos:

Identificar se há ambiente informatizado na escola.

Identificar os recursos de TICs disponíveis e há quanto tempo são realizadas as atividades docentes no ambiente informatizado.

Descrever como são administradas as atividades dos ambientes informatizados: coordenação, manutenção, como são adquiridos, apoio diretivo, organização de horários e avaliação.

Descrever a política da equipe diretiva para a utilização dos ambientes informatizados na prática docente.

Analisar os programas utilizados: como e porque são utilizados.

Analisar os conteúdos e como são avaliados.

Identificar se existe trabalho interdisciplinar, transdisciplinar ou multidisciplinar.

Analisar os principais problemas enfrentados pelos professores.

Analisar a percepção dos professores e equipe diretiva sobre o uso das TICs em sala de aula.

Descrever as sugestões apresentadas pelos professores e equipe diretiva para melhor utilização das TICs em sala de aula.

Analisar a percepção dos alunos sobre o trabalho realizado no ambiente informatizado na escola.

Descrever as sugestões apresentadas pelos alunos e equipe diretiva para melhor utilização das TICs em sala de aula.

Identificar os referenciais teóricos utilizados pelos professores no seu trabalho docente no ambiente informatizado.

Analisar o impacto deste trabalho no ambiente escolar

\section{Metodologia}

\section{Tipo de pesquisa}

A pesquisa foi influenciada e planejada de acordo com as experiências anteriores do mestrando e foi do tipo exploratória, buscando identificar particularidades do município de Alvorada e, segundo Gil (2010, p. 41) “As pesquisas exploratórias têm como propósito proporcionar maior familiaridade com o problema, com vistas a tornálo mais explícito ou a construir hipóteses. Seu planejamento tende a ser bastante flexível, pois interessa considerar os mais variados aspectos relativos ao fato ou fenômeno estudado. A coleta de dados pode ocorrer de diversas maneiras, mas geralmente envolve: 1 . Levantamento bibliográfico; 2. Entrevistas com pessoas que tiveram experiência prática com o assunto; e 3. Análise de exemplos que estimulem a compreensão (SELLTIZ et AL., 1967, p.63).”

Da mesma forma ela também adota o tipo descritivo, buscando informar como são as políticas públicas municipais e conforme Gil (2010, p. 42) “As pesquisas descritivas têm como objetivo a descrição das características de determinada população. Podem ser elaboradas também com a finalidade de identificar possíveis relações entre variáveis. São em grande número as pesquisas que podem ser classificadas como descritivas e a maioria das que são realizadas com objetivos profissionais provavelmente se enquadra nesta categoria. Entre as pesquisas descritivas, salientam-se aquelas que têm por objetivo estudar as características de um grupo: sua distribuição por idade, sexo, procedência, nível de escolaridade, estudo de saúde física e mental, ..."

E a pesquisa também contempla o tipo explicativa, buscando demonstrar como são utilizados os Ais nas escolas municipais e, segundo Gil (2010, p. 42) "As pesquisas explicativas têm como propósito identificar 
fatores que determinam ou contribuem para a ocorrência de fenômenos. Estas pesquisas são as que mais aprofundam o conhecimento da realidade, pois têm como finalidade explicar a razão, o porquê das coisas."

\section{População}

A população desta pesquisa refere-se aos alunos, professores e equipe diretiva do $9^{\circ}$ ano das escolas públicas do munícipio de Alvorada - RS, Brasil.

\section{Amostra da pesquisa}

A amostra aceitante e respondente desta pesquisa é constituída de 109 pessoas, distribuídas da seguinte forma: 60 professores da sala de aula de escolas municipais de Alvorada e 49 alunos de 3 turmas do nono ano de 2 escolas municipais.

\section{Instrumentos}

$\mathrm{O}$ instrumento adotado na pesquisa foi o questionário com questões abertas e fechadas para a equipe diretiva, professores e alunos.

O questionário foi construído de acordo com a experiência do mestrando em outras pesquisas, assim como seus anos de vivência com o uso das TICs em sala de aula e como professor da rede municipal de Alvorada.

A primeira parte do questionário apresenta o perfil dos respondentes, seguido do processo ensino-aprendizagem relacionado às TICs, do corpo social da escola, passando pelas instalações físicas e finalizando com as metodologias de ensino utilizadas, de modo que possam elucidar as questões levantadas nesta pesquisa.

As respostas das questões abertas do instrumento questionário são apresentadas em categorias. Os resultados finais das questões abertas são apresentados mediante um quadro sinóptico.

\section{Justificativa da Amostra}

Esta amostra foi definida por acessibilidade, de acordo com a receptividade e contato inicial telefônico ou pessoal com as direções das escolas para a aplicação dos questionários online diretamente com os professores, no dia da reunião pedagógica e com os alunos nos seus horários de aula.

E também por intencionalidade visando apenas que turmas de nono ano das escolas municipais respondessem a pesquisa, com seus respectivos professores e alunos, ocasionando uma maturidade e agilidade maior, por parte dos alunos, no preenchimento dos questionários.

\section{Análise de dados}

No trabalho original são apresentadas 56 figuras com os devidos comentários. O autor está a disposição para maiores informações aos interessados.

\section{Alunos}

Quais os principais problemas encontrados no decorrer das aulas com o uso de TIC?

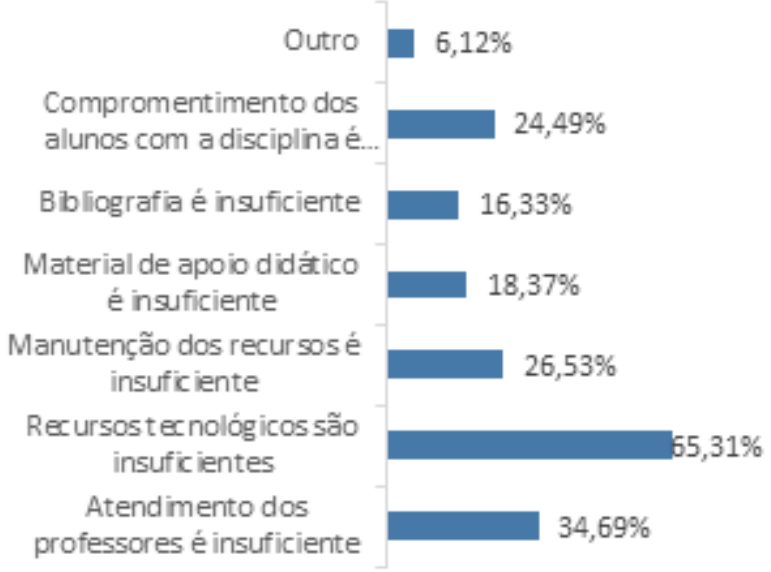

Figura 1 - Principais problemas alunos

A figura 1 mostra as respostas dos alunos que revela ser bem semelhante a dos professores em todas as opções e a mais marcada de todas foi a de que os recursos tecnológicos são insuficientes em que 32 respondentes marcaram esta opção, ou seja, mais de $65 \%$ acredita que são necessários muito mais recursos TICs para atender a demanda da escola. Com índices bem menores e próximos entre si, com uma diferença de cerca de $10 \%$ entre eles, temos que 17 alunos marcaram que o atendimento dos professores é insuficiente, 13 que a manutenção dos recursos é insuficiente e 12 que o compromentimento dos alunos com a disciplina é insuficiente (com índices de aproximadamente 34\%, $26 \%$ e $24 \%$ respectivamente) e por fim vem o material de apoio didático é insuficiente, com 9 alunos respondentes e a bibliografia é insuficiente por 8 alunos. Tivemos ainda 3 outras respostas em que uma delas era que não havia nenhum problema e a falta de interesse e brincadeira em algumas disciplinas.

\section{Professores}

Quais os principais problemas encontrados no decorrer das aulas com o uso de TIC?

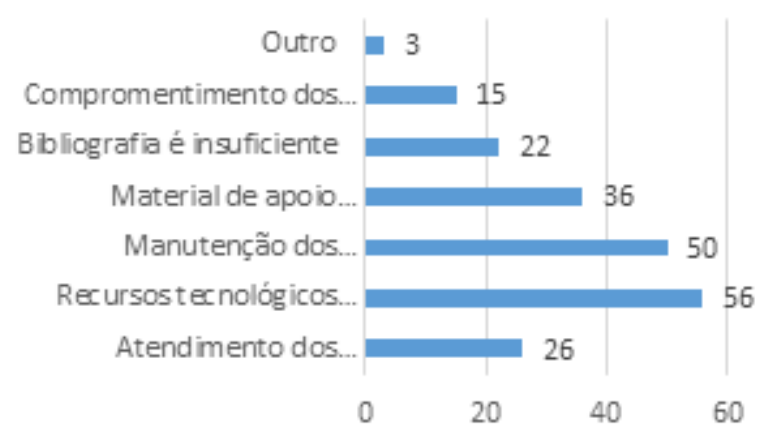

Figura 2 - Principais problemas professores

A figura 2 deixa bem claro que os recursos tecnológicos são insuficientes, com mais de $90 \%$ dos professores (56 de um total de 60), para a eficiente utilização dos recursos TICs em sala de aula, além de $80 \%$ ainda relatar que a manutenção dos recursos existentes também é ineficiente, demonstrando que sua mantenedora fez pouco investimento em recursos TICs e não ter sequer dado manutenção aos poucos recursos que 
existem, ou se ocorreu foi de forma não satisfatória. Temos ainda que $60 \%$ dos professores (36 respondentes) acredita que o material de apoio didático não é suficiente para a demanda de alunos em cada escola. E Um pouco abaixo de 40\% (22 respondentes) afirmando que a bibliografia é insuficiente. E aqui temos então uma realidade nas escolas da rede municipal de Alvorada que deixa a desejar nestes pontos acima destacados.

Ainda temos que, com um índice um pouco acima de $40 \%$ (26 respondentes), o atendimento dos professores é insuficiente, algo preocupante e que não condiz com as resposta das questões anteriores já que era notado um comprometimento dos professores com seus alunos ou podemos então dizer que este atendimento dos professores poderia ser mais efetivo junto aos alunos. Fica aqui uma questão que pode ser melhor analisada em pesquisas posteriores.

Por último, com um índice de $25 \%$ temos o comprometimento dos alunos com a disciplina insuficiente, revelando um certo desleixo por parte dos alunos com seus estudos ou até uma estratégia equivocada por parte do professor na condução de sua disciplina.

\section{Conclusões}

Nesta pesquisa sobre a utilização dos ambientes informatizados na rede municipal de Alvorada pudemos verificar que as questões de pesquisa foram de modo geral esclarecidas e a seguir fazemos a análise de cada uma delas.

A primeira questão era identificar se há ambiente informatizado na escola e conforme próprio conhecimento do pesquisador e conversas realizadas com os professores, alunos e equipe diretiva das escolas, existem sim em todas as escolas, mas a pesquisa demonstrou que muitos têm poucos computadores funcionando ou ainda não estão mais nem instalados, e isso devido ao fato de todos os computadores que eram do AI estarem sucateados, terem sido roubados ou modificado o local da sala do AI e não ter sido feito a ligação da rede física de energia e internet. E aqui também podemos dizer que a SE de Alvorada realizou um fornecimento de notebooks para todas as escolas da rede, de modo que fosse possível ter um novo AI ou até na própria sala de aula da turma, mas que em algumas escolas não foram nem tirados das caixas, com a equipe diretiva aguardando que seja colocado uma internet que funcione para disponibilizar estes equipamentos para todos e em outras escolas já foram roubados. E aqui fica bem claro também que, tanto na visão dos professores como dos alunos estes recursos são insuficientes para a demanda existente.

Como segunda questão temos que identificar os recursos TICs disponíveis e há quanto tempo são realizadas as atividades docentes no ambiente informatizado. Os recursos disponíveis são TV/DVD dominando e em seguida o computador e bem mais atrás aparece o celular, muito embora isso seja uma incongruência pois existe uma lei municipal que proíbe o uso do celular em sala de aula e nas próprias regras das escolas sempre aparece a proibição do uso do celular em sala de aula, assim como nas reuniões pedagógicas dos professores seguidamente aparece como um problema o uso do celular pelos alunos. Estes três recursos TICs se assemelharam tanto para professor como para aluno. Ainda na visão do professor aparecem outras opções como tablet, lousa digital, jogos e até livros (que pela pergunta devem ser digitais). Já para os alunos não aparece nenhuma outra opção.

Em seguida aparecia: descrever como são administradas as atividades dos ambientes informatizados. Esta questão foi respondida tanto no questionário aplicado pelo pesquisador como nas conversas informais com os professores e alunos na aplicação do mesmo. A coordenação é realizada pela direção que marca os horários para que os professores possam utilizar o AI e distribui de modo que possam ser utilizados pelo maior número possível de alunos. Para adquirir os recursos TICs, praticamente é a SE que toma conta desta parte, assim como a manutenção destes equipamentos, com algumas escolas maiores eventualmente efetuando a compra e manutenção. A avaliação das atividades depende muito do professor, sendo mais comum ser realizada com os professores dos anos finais do que com os anos iniciais, com os alunos corroborando esta informação, já que a grande maioria afirmou que existia esta avaliação. $\mathrm{O}$ apoio diretivo para a realização e utilização de atividades com TICs depende muito da escola, sendo mais comum nas escolas que possuem anos finais.

Em seguida temos duas questões que vamos explanar conjuntamente por estarem relacionadas. Elas eram: analisar os programas utilizados: como e por que são utilizados e analisar os conteúdos e como são avaliados. Aqui temos uma diferenciação entre os professores e alunos. Para os professores são utilizados de forma bem distribuída todas as opções que existiam, análise de documentos audiovisuais, análise de textos, elaboração de atividades pelos alunos, exercícios, outro e trabalhos escritos, com o mais utilizado com mais de $50 \%$ dos professores escolhendo a elaboração de atividades pelos alunos e a menos escolhida os trabalhos escritos com cerca de $28 \%$. Já para os alunos foi bem diferente com mais de $60 \%$ dizendo que os trabalhos escritos são os mais utilizados e a elaboração de atividades pelos alunos com menos de $25 \%$. Sobre as avaliações e conteúdos temos para os professores um domínio da avaliação contínua e mais abaixo os trabalhos individuais e em grupo e logo em seguida prova escrita e teste. Nos alunos aparece um domínio da prova escrita e mais abaixo os trabalhos individuais e de grupo e após os testes.

Temos outra ainda que era analisar os principais problemas enfrentados pelos professores. E ficou muito claro que a internet é o principal, algo que apareceu em várias questões que não tratavam deste assunto, mas que tanto professores como alunos queriam destacar esta dificuldade. Aparecem ainda dominando que os recursos tecnológicos são insuficientes (e aqui entra a internet precária) para professores e alunos, manutenção dos recursos insuficiente (também com a internet não tendo manutenção) e material de apoio didático insuficiente, para os professores. Já para os alunos o atendimento dos professores é insuficiente e logo em seguida, quase juntas 
a manutenção dos recursos insuficiente e o comprometimento dos alunos com a disciplina insuficiente.

A próxima questão era analisar a percepção dos professores e equipe diretiva sobre o uso das TICs em sala de aula. E aqui temos algumas perguntas do questionário online que deixam claro que os recursos TICs são valiosos instrumentos pedagógicos para as aulas e que existe um certo comprometimento dos professores quando são utilizados estes recursos, já que a maioria dos professores respondeu positivamente sobre a compatibilização entre as TICs e sua disciplina, adequação entre recursos TICs e a natureza da disciplina uma grande interação entre professores e alunos nas aulas com TICs. Todas estas questões demonstraram que as TICs são necessárias nas aulas e conectadas com a realidade dos alunos.

E tínhamos que descrever as sugestões apresentadas pelos professores e equipe diretiva para melhor utilização das TICs em sala de aula. A opção que dominou amplamente foi ter mais recursos tecnológicos a disposição dos alunos, com mais de $93 \%$ dos professores marcando-a. Logo em seguida temos que deve se melhorar a manutenção dos recursos, com $88 \%$ de marcação e mais abaixo deve-se disponibilizar mais apoio didático aos alunos (65\%). Bem mais abaixo e com índices bem próximos aparecem a disponibilização de mais bibliografia, maior comprometimento dos alunos com a disciplina e maior interação professor/aluno.

Em seguida temos mais duas que também serão analisadas conjuntamente, que são: analisar a percepção dos alunos sobre o trabalho realizado no ambiente informatizado na escola e descrever as sugestões apresentadas pelos alunos e equipe diretiva para melhor utilização das TICs em sala de aula. Para os alunos as TICs aparecem diariamente em suas vidas, desde quando acordam e já estão com seus celulares em mãos, na própria sala de aula, com o uso da calculadora, rádios, e redes sociais, assim como no resto do seu dia, na TV, cinema, e nos seus computadores, então utilizar estes recursos em sala de aula é o que mais desejam, o que ficou demonstrado nas respostas do questionário. Para as sugestões, assim como nos professores a mais destacada foi que se tenham mais recursos tecnológicos a disposição dos alunos (57\%) e em seguida, bem próximas uma maior interação professor/aluno e um maior comprometimento dos alunos com a disciplina. Mais abaixo vem a melhora na manutenção dos recursos e no final, próximos de $15 \%$ vem a disponibilidade de mais apoio didático aos alunos e mais bibliografia.

E terminamos concluindo que os professores ainda carecem de formação para a utilização das TICs e em vista disso não utilizam um sistema de avaliação com recurso TIC. Os que utilizam-na visam sempre a interação com os alunos, e isso na visão dos professores como dos alunos, assim como ambos acreditam existir uma adequada relação entre professores e alunos nas atividades com uso de TIC e também ressaltam que as instalações físicas das escolas e os recursos TICs são insuficientes para atender a demanda da escola, com ênfase principalmente nas dificuldades encontradas com internet disponibilizada que é nula ou não funciona de maneira adequada por quase todo o período escolar. Os recursos TICs mais utilizados são a TV/DVD e os computadores.

As políticas públicas relacionadas às TICs ainda inexistem e devem ser elaboradas conjuntamente com os professores e até dos próprios alunos de modo que sejam feitas de acordo com a realidade de todos, visto que podemos ver que existem algumas semelhanças entre as opiniões e visões de professores e alunos, mas ainda temos algumas peculiaridades típicas de cada um.

\section{Referencias}

Almeida, M. E. \& Valente, J. A. (2011). Tecnologias e currículo: trajetórias convergentes ou divergentes. São Paulo, SP. Editora Paulus.

Almeida, M. E. \& Silva, B.D. \& Dias, P. (2013). Cenários de inovação para a educação -. São Paulo, SP. Editora Loyola.

Falavigna, G. (2013). O Ensino a distância em universidades ibero-americanas: características básicas do processo ensino-aprendizagem $e$ a utilização de tecnologias de informação $e$ comunicação (TIC). Dissertação de Pós-Doutorado em Educação, Curso de Pós-Graduação em Educação. Universidade do Minho, Braga, Portugal.

Silva, B. (2001). As tecnologias de informação $e$ comunicação nas reformas educativas em Portugal. Revista Portuguesa de Educação". Pp.111-153

Silva, B. (2011). Plano Tecnológico da Educação em Portugal: Análise dos Relatórios dos Planos TIC In Ana Paula Vilela (coord.). A Par dos Tempos que Correm. As TIC e o Centenário da República. Braga: Centro de Formação. Braga-Sul, pp.29-45

Valente, J. A. \& Almeida, F. J. (1997). Visão analítica da informática na educação no Brasil: a questão da formação do professor. Revista Brasileira de Informática na Educação. RS: Sociedade Brasileira de Computação, 1, 45-60. 